\title{
Developing a Formula to Estimate Precipitation at Ungauged Location and Analysis of Rainfall Pattern: Case Study for Rastra Bank Chowk, Pokhara, Nepal
}

\author{
Keshav Basnet, Kabita Poudel \\ Department of Civil and Geomatics Engineering, Pashchimanchal Campus, Institute of Engineering, Tribhuvan University, \\ Pokhara, Nepal
}

E-mail: basnet.keshav@gmail.com,erkabitapoudel23@gmail.com

\begin{abstract}
Pokhara receives the second highest amount of rainfall in the country, according to Department of Hydrology and Meteorology. The rainfall distribution within this small region is random. The precipitation in Pokhara is measured from limited rain gauge stations. For understanding the spatial variation, it is necessary to access the daily rainfall data at the gauged as well as ungauged stations. In view of this problem, this study is aimed at developing the formula to estimate the rainfall value at an ungauged station, Rastrabank Chowk Pokhara using the calibration and validation method. For this purpose, the daily rainfall data of the sample station was measured using standard rain gauge for a period of four months from May 13, 2020 to September 15, 2020. The analysis of the spatial distribution and variation of daily rainfall at meteorological stations as well as sample station was done to select the data for the development of the formula. Calibration and validation of formula was performed for equal period using the statistical indices NSE, $R^{2}$ and PBIAS. Calibration was performed using rainfall data of available meteorological stations of Pokhara in the first two consecutive months. From the numerous hit and trial procedures, the equation developed with rainfall data of Airport and Malepatan stations comprising of three constant values were obtained with the highest NSE and $R^{2}$. PBIAS value was then calculated for maximum NSE and $R^{2}$. In the next phase, validation of the equation for other two months (14 July- 15 September,2020) was performed to obtain maximum possible value of NSE and $\mathrm{R}^{2}$ and a smaller value of PBIAS. The equation was obtained with $0.980 \mathrm{NSE}, 0.980 R^{2}$ and $6.437 \%$ PBIAS value which indicated good agreement between observed and predicted rainfall value. Spatial rainfall pattern analysis using SURFER model demonstrated that there was a homogenous distribution of rainfall in Malepatan, Airport and sample stations. The temporal trend showed that the month July of 2020 had a higher amount of precipitation at Pokhara valley. From the HYSPLIT model, it was observed that the rainfall events in Pokhara valley was due to westerlies dominance. This study would provide the rainfall estimation techniques and hence would significantly contribute to meteorological investigations and water resource planning.
\end{abstract}

Keywords: Calibration for Rainfall Estimation, Diurnal Rainfall Variation, HYSPLIT Model, Ungauged Station Rainfall. 


\section{Introduction:}

Precipitation is an important element in hydrologic cycle, it helps in maintaining the atmospheric balance. The amount of rainfall that an area receives depends on the climate, location, and surrounding environment. Pokhara is a moisture convergence zone that receives some of the highest rainfall in Nepal [1]. Pokhara valley is surrounded in the east, north and northwest by high mountains. These act as a barrier and induce precipitation from orthographically lifted humid air. Precipitation results also from mountainvalley flows that are drawn into the area each day. As indicated by WRCO, Kaski, the total annual rainfall in Pokhara valley is roughly 4000-5000 mm (Source: WRCO, Kaski).

The availability and distribution of rainfall recording instrument is limited [2]. There are five meteorological stations placed at Pokhara Airport, Lamachaur, Malepatan, Begnas and Nirmal Pokhari. The distribution of precipitation has high spatial variation in Pokhara [3]. The rainfall data of nearby gauged and ungauged sites are essential for meteorological investigation, for understanding the spatial variation, water resource planning and management.

However, missing data is frequent problem in climatology. There are number of techniques for estimating rainfall data when few or no observed data are available when expected data are missing. Mathematical estimation methods, estimation based on physical relationship, spatial estimation methods and time series estimation are the precipitation predicting techniques. In all cases, values estimated must be realistic and consistent with physical considerations. It is therefore important to verify that assumptions made in applying the estimation model are fulfilled [4].

The estimation of rainfall data at ungauged sites by developing the formula by the method of calibration and validation can be useful for determining the insitu rainfall data. This methodology can be utilized for assessing the spatial distribution of rainfall within Pokhara valley.

Pokhara is a metropolitan city in Nepal, which serves as the capital of Gandaki Pradesh. This study focuses on estimating the rainfall value at
WRCO office (sample station), Rastra Bank Chowk, Pokhara (Fig. 1). It is situated at $28^{\circ} 12^{\prime}$ $20.23^{\prime \prime}$ north latitude and $83^{\circ} 58^{\prime} 24.98^{\prime \prime}$ east longitude at an elevation of $2708 \mathrm{ft}$ above mean sea level.

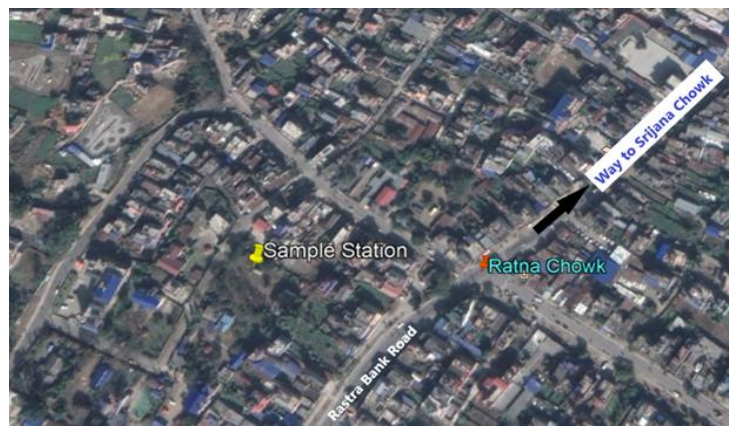

Figure 1: Location of the study area

This study's main objective is to develop a formula for calculating the rainfall amount for an ungauged location using the data of surrounding meteorological stations. Specifically, the study intends to achieve the following additional objectives.

- To analyze the rainfall pattern for the ungauged location.

- To compare the rainfall pattern of the location with surrounding stations.

- To compute air parcel trajectory using HYSPLIT model.

This research excludes the physical parameters (elevation, latitude, longitude) as well as physical processes (sunshine duration, cloudiness) at the meteorological stations i.e. only the rainfall data were used for deriving the equation. As physiographic and synoptic characteristics vary at different places, the derived formula cannot be directly applicable to other sites. Due to the project time constraints, only four months of rainfall data of 2020 monsoon was measured and just two month periods were used for calibration and validation respectively. For the precise determination of the formula, continuation of the study can be accomplished.

\section{Methodology:}

The development of formula includes three steps: data collection, calibration and validation. The basic framework of the proposed method is depicted in Fig. 2, where the data of sample station can be anticipated by generating an equation. 


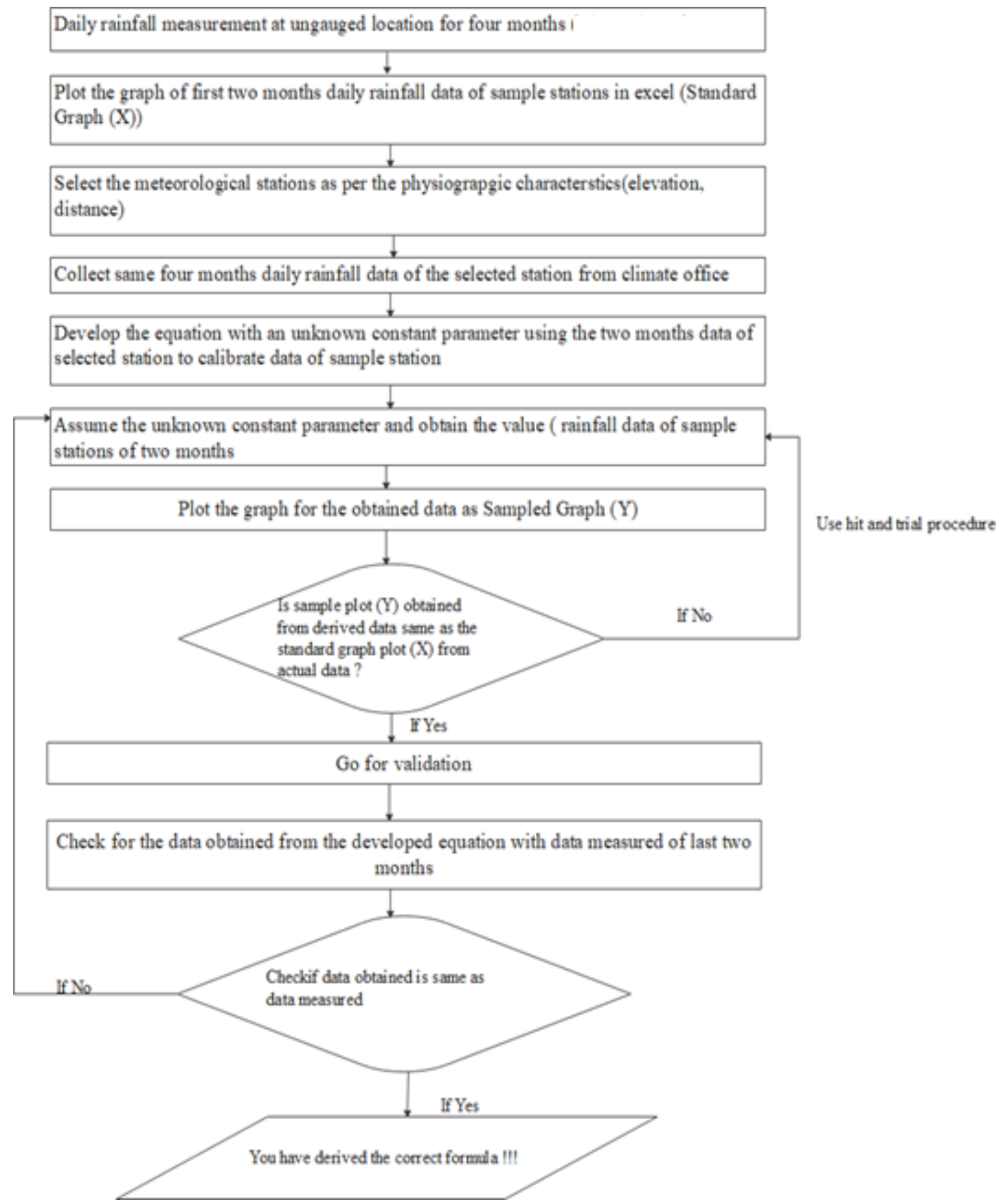

Figure 2: Research methodology framework for development of formula

\subsection{Data Collection:}

At first, daily rainfall was measured in sample site for four and half months' period (May 13 to September 30, 2020) using the ordinary rain gauge meeting WMO standard. The rain gauge in the climate office as shown in Fig. 3 was not in use. Therefore, that gauge was used for this study to measure the daily precipitation. The ordinary rain gauge meeting the WMO standard consist of an 8-inch diameter funnel emptying into a graduated cylinder, which fits inside a larger container that is 8 inches in diameter and $1 \mathrm{~m}$ tall. If the rainwater overflows the graduated inner cylinder, the larger outer container will catch it. When measurements are taken, the height of the water in the small graduated cylinder is measured, and the excess overflow in the large container is carefully poured into 
another graduated cylinder and measured to give the total rainfall [5].

The pictures attached in Fig. 4 display measurement of rainfall from standard rain gauge in this study. As mentioned above, the rainfall recording was taken starting from date May 13 to 30 September, 2020 as demonstrated in a Table 3. The data from the meteorological stations were the input for calculation. The secondary data of four meteorological stations (Airport, Lamachaur, Begnas and Malepatan) was acquired from WRCO office. The details of meteorological stations in Table 2 illustrates that Begnas, lamachaur and Nirmal Pokhari stations show diferent physical patterns with respect to longitude, elevation and topography respectively. However, as Airport and Malepatan stations are situated nearby the sample station, the physiographic characteristic are similar. The secondary data of the meteorological stations Begnas, Lamachaur, Malepatan, Pokhara Airport was acquired from the office of hydrology and meteorology.

\subsection{Calibration and Validation:}

For the selection of meteorological stations for calibration and validation the physiographic characteristics (elevation, latitude, longitude, distance from the sample station) and the rainfall pattern was taken into account. The first two months of rainfall data of the sample station from May 13, 2020 to July 13, 2020 was plotted in the graph (Standard graph). An equation with an unknown constant parameter using the daily rainfall data of the selected meteorological station was assumed. By presuming the constant the solution of the equation was then plotted for two months' data (May 13 to July 13). The graph thus plotted referred to as sampled graph. For calibration, the standard graph and sample graph should have a good fit. Three statistical indices: Coefficient of Determination $\left(R^{2}\right)$, Nash-Sutcliffe Efficiency (NSE), Percent Bias (PBIAS) were used for calibration and validation [6].

\subsubsection{Nash-Sutcliffe Efficiency (NSE):}

The Nash-Sutcliffe efficiency (NSE) is a normalized statistic that determines the relative magnitude of the residual variance ("noise") compared to the measured data variance ("information") (Nash and Sutcliffe, 1970) [7]. Table 1 shows the criteria for Nash-Sutcliffe efficiency (NSE) coefficient [8].

Formula:

$N S E=1-\frac{\sum_{t=1}^{T}\left(Q_{m}^{t}-Q_{0}^{t}\right)^{2}}{\sum_{t=1}^{T}\left(Q_{0}^{t}-\overline{Q_{0}}\right)^{2}}$

Where,

$Q_{0}^{t}=$ Mean of observed value at time $t$

$Q_{m}^{t}=$ Modeled Value

$Q_{0}=$ Mean of observed value

Table 1:Criteria for Nash-Sutcliffe efficiency (NSE) coefficient

\begin{tabular}{lc}
\hline \multicolumn{1}{c}{ Properties } & NSE Value \\
\hline \hline Very good & $0.75-1$ \\
good & $0.65-0.75$ \\
Satisfactory & $0.5-0.65$ \\
Unsatisfactory & $<0.5$ \\
\hline \hline
\end{tabular}

(Source: Evaluation of Nash-Sutcliffe efficiency (NSE) Index)

\subsubsection{Coefficient of Determination $\left(\boldsymbol{R}^{2}\right)$ :}

The coefficient of determination $\left(R^{2}\right.$ or $\mathrm{r}$ squared) is a statistical measure in a regression model that determines the proportion of variance in the dependent variable that can be explained by the independent variable. The relationship between two variables is generally considered strong when their $R^{2}$ value is larger than 0.7 [6].

Formula:

$$
R^{2}=1-\frac{\sum_{i}\left(y_{i}-\widehat{y_{1}}\right)^{2}}{\sum_{[}\left(y_{i}-y^{2}\right.}
$$

where,

$y_{i}=$ Observed Value

$\widehat{y_{k}}=$ Simulated Value

$\bar{y}=$ Mean Value

\subsubsection{Percent Bias (PBIAS):}

The Percent Bias calculates the volume difference between simulated and observed 
streamflows, with a positive value indicating The number of hit and trial procedures was that the model under predicts observed flows.

Formula:

$$
\text { PBAIS }=\frac{\Sigma\left(Q_{o b s}-Q_{\text {sim }}\right)}{\Sigma\left(Q_{o b s}\right)} \times 100
$$

Where,

$$
\begin{aligned}
& Q_{\text {obs }}=\text { Observed Value } \\
& Q_{\text {sim }}=\text { Simulated Value }
\end{aligned}
$$
adopted for the best fit between standard and sample graphs i.e. for the maximum possible value of NSE and $R^{2}$. The equation with the calibrated constant value was then validated for two months of data of the sample station from July 14 - September 15, such that it lends the highest NSE and $R^{2}$ value and a smaller value of PBIAS. If the constant value didn't yield the highest NSE and $R^{2}$ value in validation, then the validation was performed for another constant value with the highest NSE and $R^{2}$ obtained by calibration.

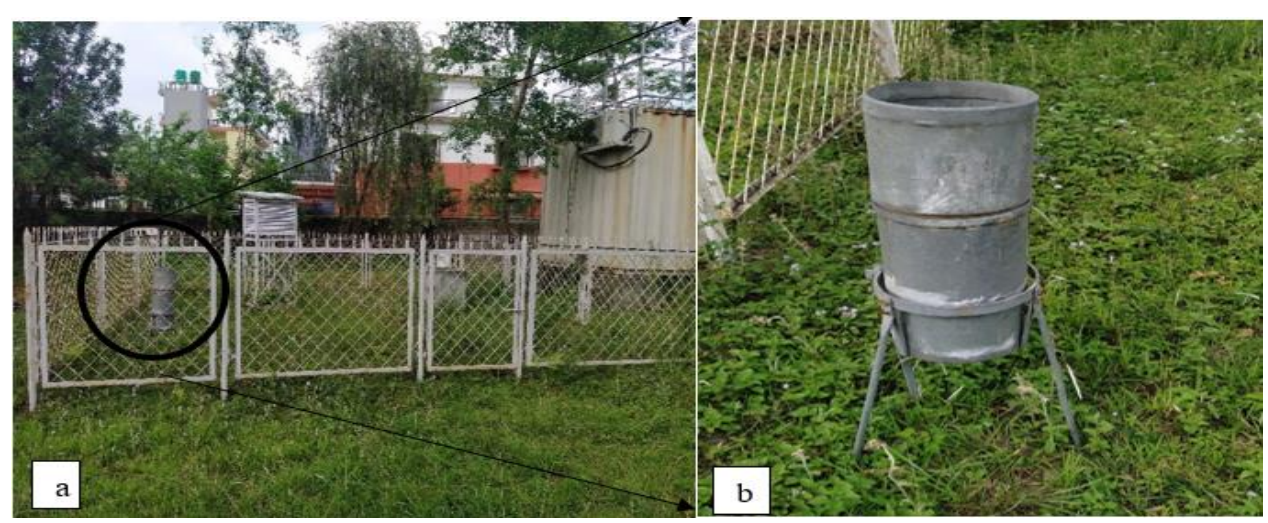

Figure 3: Sample Station; a) WRCO unused climate instrument b) Ordinary rain gauge

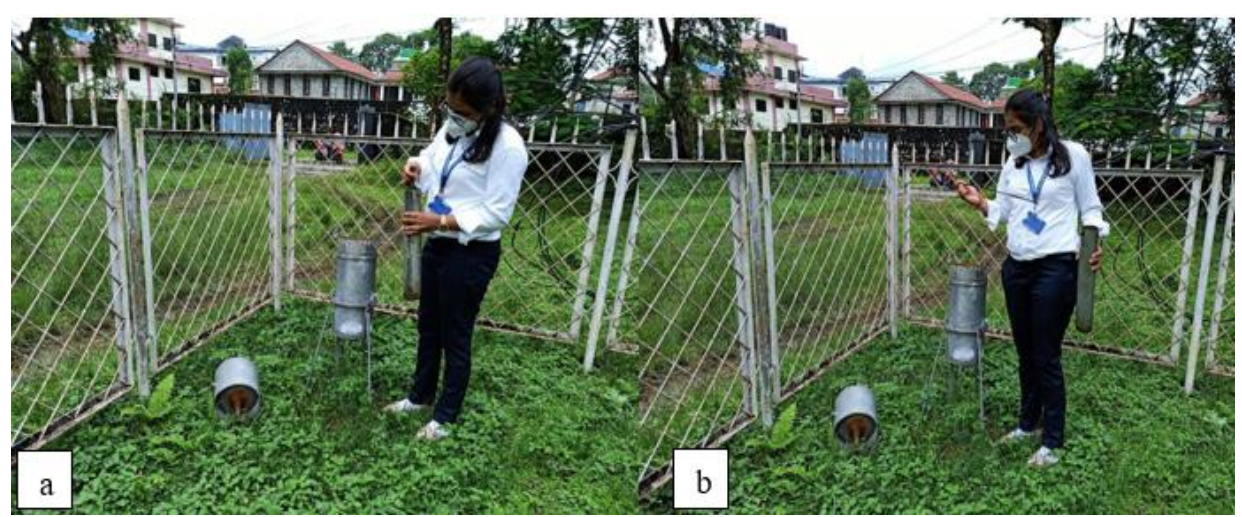

Figure 4: Rainfall measurement; a) Dipping scale in inner cylinder, b) Reading scale

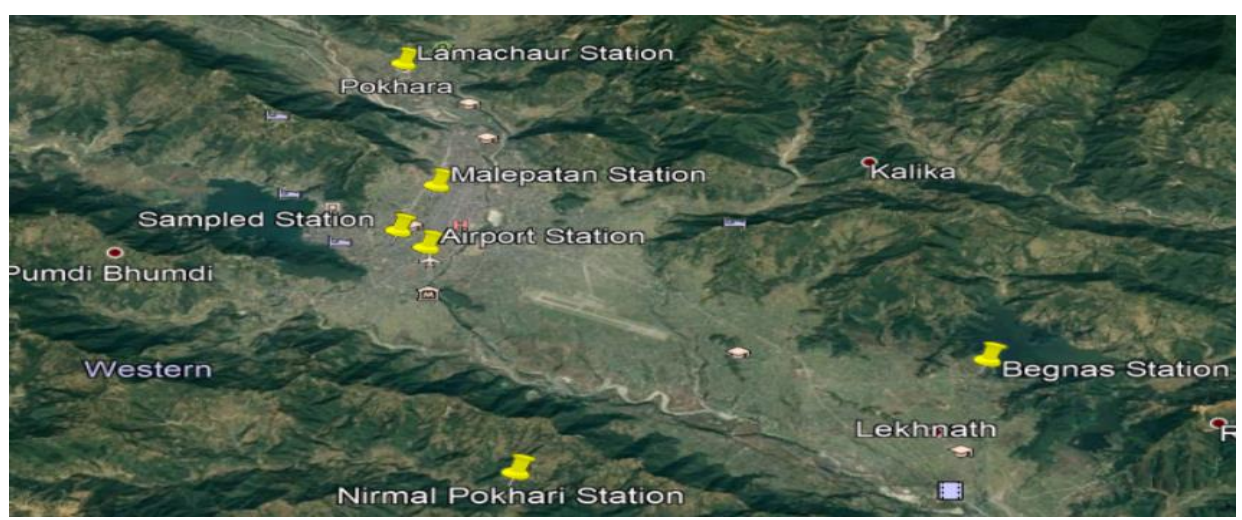

Figure 5: Study area showing location of stations (Source: Google Earth,2020) 
Himalayan Journal of Applied Science and Engineering (HiJASE), Vol. 2, Issue 2, Nov., 2021

Table 2: Meteorological station details

\begin{tabular}{|c|c|c|c|c|c|}
\hline Station Name & Latitude & Longitude & $\begin{array}{c}\text { Elevation } \\
\text { (m) }\end{array}$ & $\begin{array}{c}\text { Distance } \\
\text { Reference to } \\
\text { Sample Station } \\
(\mathbf{k m})\end{array}$ & $\begin{array}{c}\text { Physical Difference in } \\
\text { Reference to Sample } \\
\text { Station }\end{array}$ \\
\hline Airport & $2812.009 \mathrm{~N}$ & $8358.771 \mathrm{E}$ & 827 & 1.3 & Similar \\
\hline Malepatan & $2813.110 \mathrm{~N}$ & $8358.452 \mathrm{E}$ & 842 & 1.7 & Similar \\
\hline Lamachaur & $2815.701 \mathrm{~N}$ & $8358.124 \mathrm{E}$ & 1050 & 6.4 & High Elevation \\
\hline Nirmal Pokhari & $2808.713 \mathrm{~N}$ & $8400.464 \mathrm{E}$ & 854 & 16 & $\begin{array}{l}\text { Longitude, Hills Nearby } \\
\text { Longitude, Hills \& }\end{array}$ \\
\hline Begnas & $2809.963 \mathrm{~N}$ & $8405.359 \mathrm{E}$ & 679 & 14.4 & $\begin{array}{c}\text { Watersheds nearby, } \\
\text { elevation }\end{array}$ \\
\hline
\end{tabular}

Table 3: Data measured in sample station (WRCO office)

\begin{tabular}{|c|c|c|c|c|c|}
\hline \multirow[t]{2}{*}{ Date } & \multicolumn{5}{|c|}{ Rainfall (mm) } \\
\hline & May & June & July & August & September \\
\hline 1 & & 4 & 0 & 93 & 118 \\
\hline 2 & & 0 & 0 & 6.86 & 67 \\
\hline 3 & & 8.1 & 58.4 & 0 & 30 \\
\hline 4 & & 18.4 & 36.2 & 0.5 & 0 \\
\hline 5 & & 7.7 & 0 & 47 & 120 \\
\hline 6 & & 18.5 & 30.2 & 30 & 50 \\
\hline 7 & & 32 & 41 & 3.8 & 32 \\
\hline 8 & & 59.8 & 4.4 & 4.9 & 118 \\
\hline 9 & & 107.2 & 154.5 & 6.5 & 57 \\
\hline 10 & & 0 & 240 & 130.5 & 52 \\
\hline 11 & & 0 & 11.1 & 33.5 & 116 \\
\hline 12 & & 8.2 & 144.6 & 65.5 & 7 \\
\hline 13 & 21 & 5.3 & 31.8 & 25.5 & 7 \\
\hline 14 & 11.2 & 15 & 35 & 6.5 & 20 \\
\hline 15 & 7 & 59.4 & 22.5 & 163 & 170 \\
\hline 16 & 26.2 & 24.1 & 5.3 & 9 & 63 \\
\hline 17 & 13 & 18.1 & 31 & 8.5 & 94 \\
\hline 18 & 0 & 8.2 & 14.1 & 20 & 44 \\
\hline 19 & 46.5 & 66.3 & 44 & 23 & 14 \\
\hline 20 & 1.3 & 82 & 103.7 & 0.5 & 0 \\
\hline 21 & 0 & 36.1 & 110 & 16 & 0 \\
\hline 22 & 0 & 7.4 & 6.3 & 0 & 16 \\
\hline 23 & 88 & 12.3 & 64 & 35 & 53 \\
\hline 24 & 37.2 & 5.5 & 66 & 87 & 80 \\
\hline 25 & 20 & 0 & 44 & 73 & 11 \\
\hline 26 & 19.3 & 6.4 & 0.8 & 0 & 98 \\
\hline 27 & 58.1 & 81 & 131.5 & 3 & 0.2 \\
\hline 28 & 24.2 & 32.3 & 7.3 & 16 & 0.3 \\
\hline 29 & 7.5 & 39.3 & 91.9 & 7 & 0 \\
\hline 30 & 0.8 & 43.5 & 0.8 & 0 & 0 \\
\hline 31 & 0.7 & & 52 & 21 & 0 \\
\hline
\end{tabular}

\subsection{Rainfall Pattern Analysis:}

Diurnal variations of precipitation trend of four meteorological stations and sample station for four months (May - August) was plotted using
Excel tool. The spatial distribution of rainfall on meteorological \& sample station on a monthly basis within Pokhara valley for four months was diagrammatically represented. Mapping of spatial variation was done using Surfer tool. 


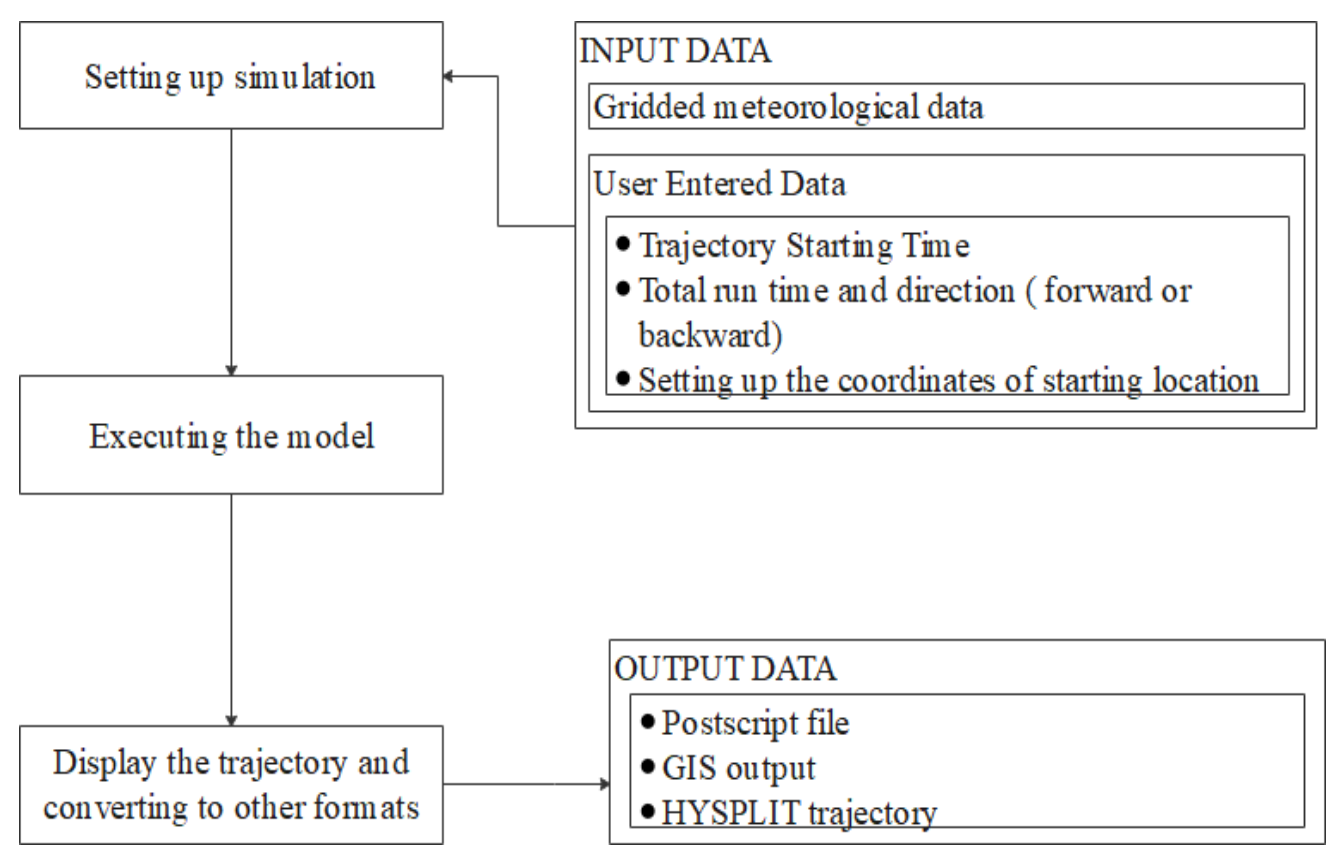

Figure 6: Research framework to compute air parcel

\subsection{HYSPLIT Model:}

HYSPLIT model was used to compute wind trajectories of the daily rainfall events at a sample station. The basic trajectory calculation consists of three steps: setup, run and display as illustrated in the Fig. 6. For HYSPLIT trajectory setting up, trajectory setup menu was used to enter the information such as starting time, starting locations, total run time, direction, top of model, vertical motion method, output and meteorological files. Then, the model simulation was started from the trajectory run model tab. The trajectory display menu provided for several options for output type as output postscript.

Hysplit figures were plotted for each extreme rainfall event at a sample station of every month of monsoon season from June to September, 2020. The backward trajectory at three levels 500,1500 , and 2500 meters above ground level at the sample station for 24 hours run time was formed. Once the model is executed, on selecting the display option, the trajectory was displayed in PDF.

\section{Results and Discussion:}

The data of the sample station was collected as mentioned in the research methodology.

\subsection{Selection of Station:}

The analysis of daily rainfall data of the sample station and meteorological stations was done for the selection of the meteorological station for calibration. The rainfall variation of Begnas and sample station was quite high. The average daily variation was $22.71 \mathrm{~mm}$ as shown in Table 4 . The rainfall distribution has been influenced because latitude, longitude, elevation other physiographic characteristics are different in these two stations.

Table 4: Rainfall variation in relation to sample station

\begin{tabular}{ccc}
\hline Station & $\begin{array}{c}\text { Average daily } \\
\text { variation }(\mathbf{m m})\end{array}$ & $\begin{array}{c}\text { Daily maximum } \\
\text { difference }(\mathbf{m m})\end{array}$ \\
\hline \hline Malepatan & 6.92 & 39.00 \\
Airport & 3.99 & 26.40 \\
Begnas & 22.71 & 225.20 \\
Lamachaur & 18.83 & 115.90 \\
\hline \hline
\end{tabular}

Table 4 shows the high discrepancy of rainfall in Lamachaur and sample station as the average daily variation and the maximum daily difference were $18.83 \mathrm{~mm}$ and $115.9 \mathrm{~mm}$ respectively. Lamachaur station is at higher elevation compared to other meteorological stations. The deviation in this characteristics affects the rainfall pattern too. Hence, for determining the formula, consideration of the Lamachaur rainfall station did not seem to be reasonable. Malepatan station shows a similar rainfall pattern as that of the sample station. The average daily variation was $6.92 \mathrm{~mm}$ and maximum daily variation was $18.8 \mathrm{~mm}$ (Table 4). Since, the distribution of rainfall is 
homogenous in these two stations, and are situated at the identical latitude and longitude; Malepatan station was included for the development of the formula. The rainfall in the Airport and the sample station is uniformly distributed with an average daily variation of $3.99 \mathrm{~mm}$ and the maximum difference of 26.4 $\mathrm{mm}$ (Table 4).

\subsection{Hit and Trial Procedure for Calibration}

\subsubsection{First Trial}

Firstly, the equation was developed taking into account all four stations. The graph thus obtained is shown in the Fig. 7. The NSE, $R^{2}$ values were calculated which were in the range 0.8- 0.90 as demonstrated in Table 5.

Table 5: Trials for calibration of formula $\left(M_{\mathrm{r}}+A_{r}+B_{\mathrm{r}}+L_{\mathrm{r}}\right) / C$

\begin{tabular}{ccc}
\hline \multicolumn{3}{c}{$\left(\boldsymbol{M}_{\mathbf{r}}+\boldsymbol{A}_{\mathbf{r}}+\boldsymbol{B}_{\mathbf{r}}+\boldsymbol{L}_{\mathbf{r}}\right) / \boldsymbol{C}$} \\
Constant Values $(\boldsymbol{C})$ & NSE & $\boldsymbol{R}^{\mathbf{2}}$ \\
\hline 3.95 & 0.837 & 0.903 \\
3.5 & 0.893 & 0.903 \\
4.1 & 0.848 & 0.903 \\
4.3 & 0.827 & 0.903 \\
\hline \hline
\end{tabular}

From the graph as well as NSE, $R^{2}$ values it was observed that the consideration of all four stations didn't give best fit. Hence, only Airport and Malepatan stations which showed similar physical and climatological patterns were considered for the development of formula.

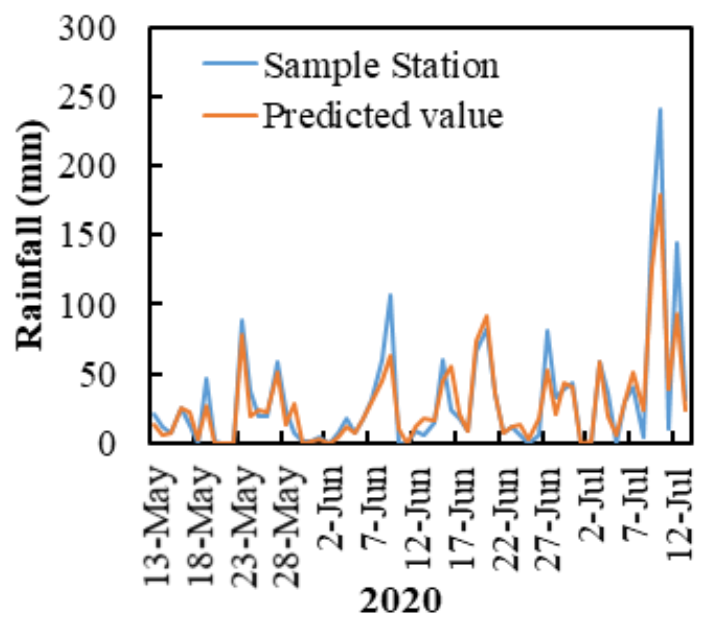

Figure 7: Graph for calibration using formula $\left(M_{\mathrm{r}}+A_{\mathrm{r}}+B_{\mathrm{r}}+L_{\mathrm{r}}\right) / 3.95$

\subsubsection{Second Trial}

In this trial, daily rainfall data of Airport and Malepatan stations were used to develop an equation. Three different constant $(a, b, c)$ were used to form the Equation 4:

$$
S_{\mathrm{r}}=\mathrm{a} \times M_{\mathrm{r}}+\mathrm{b} \times A_{\mathrm{r}}+\mathrm{c}
$$

NSE and $R^{2}$ values were calculated assuming different constant values through hit and trial procedure as depicted in Table 6 . The maximum possible NSE and $R^{2}$ values obtained were 0.980 and 0.980 , respectively.

The graph of the observed and predicted values at sample station with highest NSE and $R^{2}$ is shown in Fig. 8.

Table 6: Trials for calibration of formula $\mathrm{a} \times M_{\mathrm{r}}+\mathrm{b} \times A_{\mathrm{r}}+\mathrm{c}$ for highest NSE and $R^{2}$

\begin{tabular}{ccccc}
\hline \multicolumn{5}{c}{$\mathbf{a} \times \mathbf{M}_{\mathbf{r}}+\mathbf{b} \times \mathbf{A}_{\mathbf{r}}+\mathbf{c}$} \\
$\mathbf{C}$ & $\mathbf{a}$ & $\mathbf{b}$ & $\mathbf{N S E}$ & $\boldsymbol{R}^{\mathbf{2}}$ \\
\hline 1 & 0.36 & 0.65 & 0.976 & 0.977 \\
1 & 0.35 & 0.65 & 0.977 & 0.978 \\
1.5 & 0.3 & 0.69 & 0.979 & 0.979 \\
1 & 0.22 & 0.78 & 0.980 & 0.980 \\
1.5 & 0.22 & 0.78 & 0.980 & 0.980 \\
1.5 & 0.23 & 0.78 & 0.980 & 0.980 \\
1.5 & 0.22 & 0.77 & 0.980 & 0.980 \\
1 & 0.22 & 0.77 & 0.980 & 0.980 \\
\hline \hline
\end{tabular}

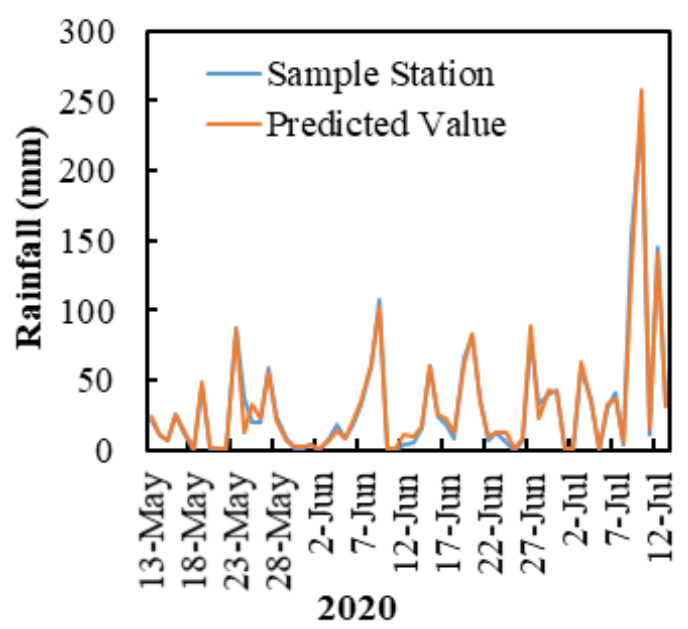

Figure 8: Graph for calibration using formula $0.22 \times A_{\mathrm{r}}+0.77 \times M_{\mathrm{r}}+1.5$

\subsubsection{Third Trial:}

In this trial, a single constant value was used to develop the equation. Airport and Malepatan stations providing the equal weightage were assessed for the calibration. Numerous hit and trial procedures were adopted to obtain maximum possible value of NSE and $R^{2}$ as mentioned in Table 7. The hit and trial procedure shows that the highest NSE and $R^{2}$ 
0.972 was obtained for the constant values ranging from $2.02-2.08$ as represented Table 7 .

Fig. 9 shows the graph of observed and predicted value at sample station using the formula $\left(M_{\mathrm{r}}+A_{\mathrm{r}}\right) / 2.02$.

Table 7: Trials for calibration of formula $\left(M_{\mathrm{r}}+A_{\mathrm{r}}\right) / C$ for highest NSE and $R^{2}$

\begin{tabular}{ccc}
\hline \multicolumn{3}{c}{$\left(\boldsymbol{M}_{\mathbf{r}}+\boldsymbol{A}_{\mathbf{r}}\right) / \mathbf{C}$} \\
Constant Values $(\boldsymbol{C})$ & NSE & $\boldsymbol{R}^{\mathbf{2}}$ \\
\hline 1.95 & 0.968 & 0.972 \\
1.97 & 0.970 & 0.972 \\
1.98 & 0.970 & 0.972 \\
2 & 0.971 & 0.972 \\
2.02 & 0.972 & 0.972 \\
2.02 & 0.972 & 0.972 \\
2.04 & 0.972 & 0.972 \\
2.06 & 0.972 & 0.972 \\
2.08 & 0.972 & 0.972 \\
\hline \hline
\end{tabular}

It was observed that, NSE and $R^{2}$ value obtained from the second trial (Table 6) were higher incomparison to the values obtained from first and third trial (Table 7). Therefore, the calibrated formula Equation $4\left(\mathrm{a} \times M_{\mathrm{r}}+\mathrm{b} \times A_{\mathrm{r}}+\mathrm{c}\right)$ developed in the second trial was then used for validation.

It was observed that, NSE and $R^{2}$ value obtained from the second trial (Table 6) were higher in comparison to the values obtained from first and third trial (Table 7). Therefore, the calibrated formula Equation $4\left(\mathrm{a} \times M_{\mathrm{r}}+\mathrm{b} \times A_{\mathrm{r}}+\mathrm{c}\right)$ developed in the second trial was then used for validation.

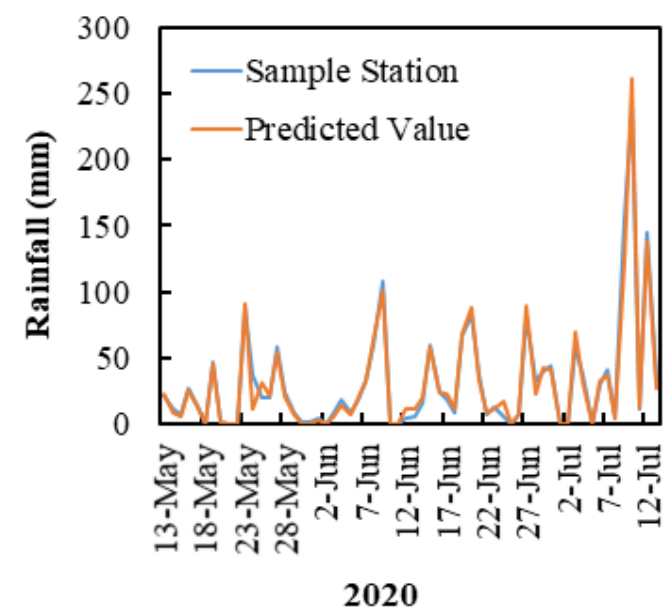

Figure 9: Graph for calibration using formula $\left(M_{\mathrm{r}}\right.$ $\left.+A_{\mathrm{r}}\right) / 2.02$

\subsection{Validation:}

The calibrated formula was then validated to obtain the maximum possible value of NSE and $R^{2}$. Further trials were made as mentioned in Table 8. PBIAS values were calculated for the highest value of NSE and $R^{2}$ i.e 0.980 . The lower value Percent Bais was obtained for the constants $\mathrm{a}, \mathrm{b}, \mathrm{c}$ with values $1.5,0.22$ and 0.77 respectively as represented by bold in Table 8 . The lower value of PBIAS indicates a good fit between the observed and predicted values.

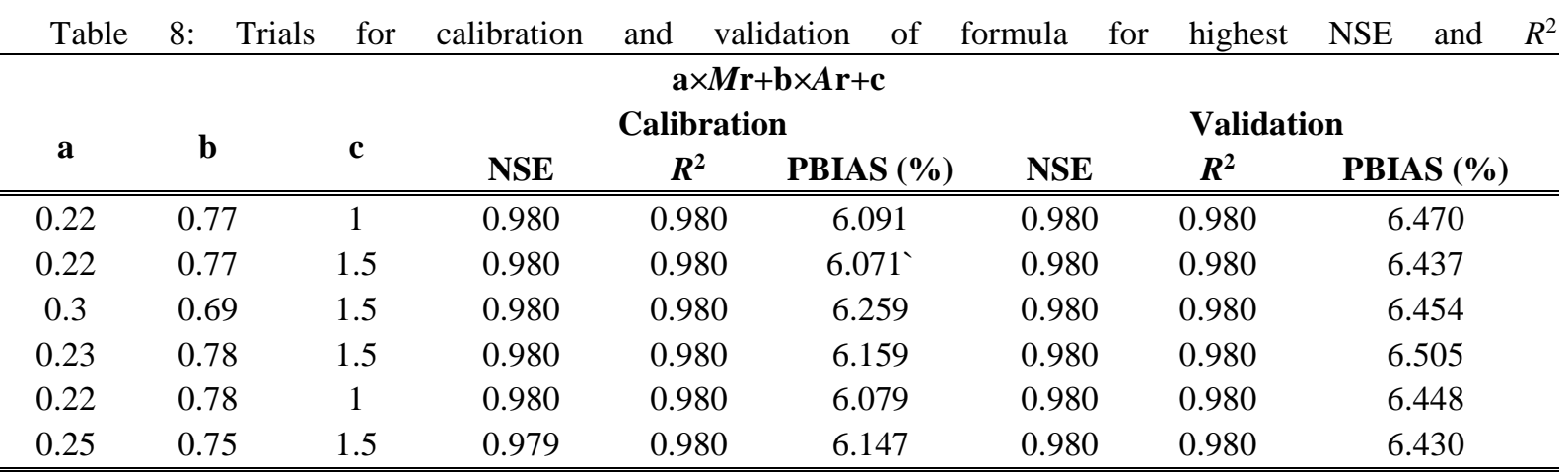

\subsection{Equation:}

The equation thus obtained was:

$S_{\mathrm{r}}=\mathrm{a} \times M_{\mathrm{r}}+\mathrm{b} \times A_{\mathrm{r}}+\mathrm{c}$

where, $S_{\mathrm{r}}=$ Sample Station Rainfall; $M_{\mathrm{r}}=$ Malepatan Station Rainfall; $A_{\mathrm{r}}=$ Airport Station Rainfall;

$a=0.22 ; b=0.77 ; c=1.5$
Therefore, $S_{\mathrm{r}}=0.22 \times M_{\mathrm{r}}+0.77 \times A_{\mathrm{r}}+1.5$

\subsection{Rainfall Pattern Analysis:}

The monthly total and highest of four months in four meteorological stations as well as sample station is represented in Table 9. On 2020 monsoon, among five stations; Malepatan station recorded the highest 24-hour rainfall of 278.8 $\mathrm{mm}$ on June while Begnas received the highest 
monthly total rainfall of $1834.5 \mathrm{~mm}$ on 2020. Lamachaur, Malepatan, sample and September. Fig. 11 shows the monthly highest of Begnas station recorded the highest 24-hour four stations from June to September 2020. The rainfall in four consecutive months from June to highest 24-hour rainfall was recorded on July, September, 2020.

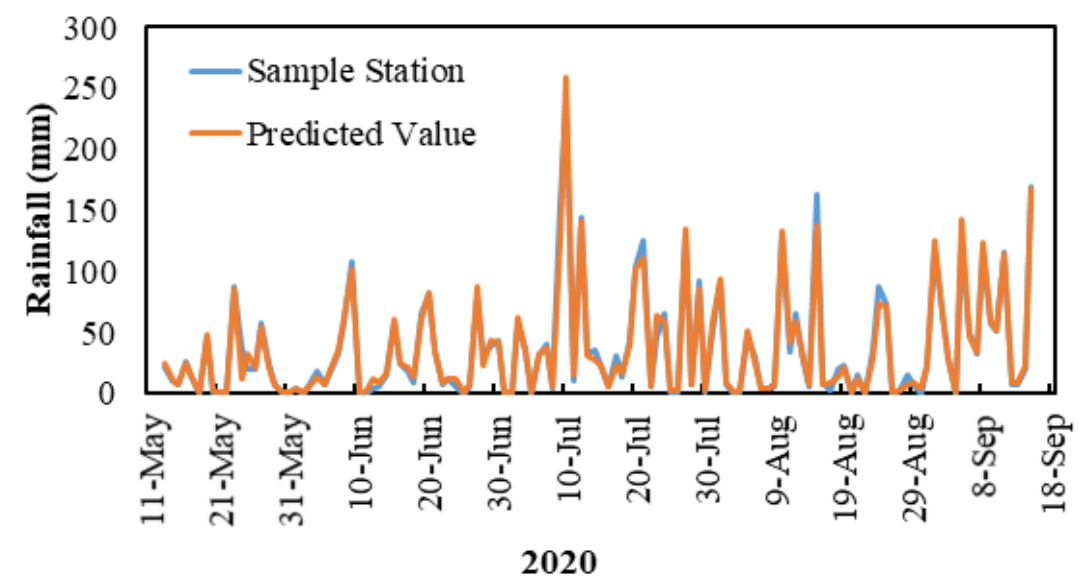

Figure 10: Graph of observed and predicted value of rainfall at sample station using formula $\left(0.22 \times M_{\mathrm{r}}+0.77 \times A_{\mathrm{r}}+1.5\right)$

Table 9: Monthly total and highest rainfall (June- September, 2020)

\begin{tabular}{|c|c|c|c|c|c|c|c|c|}
\hline \multirow{3}{*}{$\begin{array}{l}\text { Month } \\
\text { Station }\end{array}$} & \multicolumn{2}{|c|}{ June } & \multicolumn{2}{|c|}{ July } & \multicolumn{2}{|c|}{ August } & \multicolumn{2}{|c|}{ September } \\
\hline & \multirow[b]{2}{*}{ Total } & \multirow[b]{2}{*}{ Highest } & \multirow[b]{2}{*}{ Total } & \multicolumn{2}{|c|}{ Rainfall (mm) } & \multirow[b]{2}{*}{ Highest } & \multirow[b]{2}{*}{ Total } & \multirow[b]{2}{*}{ Highest } \\
\hline & & & & Highest & Total & & & \\
\hline Sample & 802.1 & 107.2 & 1535.9 & 240.0 & 930.6 & 163.0 & 1383.4 & 170.0 \\
\hline Begnas & 564.2 & 88.2 & 1018.0 & 180.8 & 1019.0 & 158.7 & 1834.5 & 248.6 \\
\hline Airport & 735.5 & 101.2 & 1485.5 & 250.9 & 865.2 & 141.1 & 1433.4 & 160.0 \\
\hline Malepatan & 936.8 & 102.5 & 1499.3 & 278.8 & 845.9 & 130.0 & 1473.8 & 183.9 \\
\hline Lamachaur & 852.6 & 140.0 & 1218.0 & 160.8 & 1022.6 & 124.0 & 1250.8 & 160.0 \\
\hline
\end{tabular}

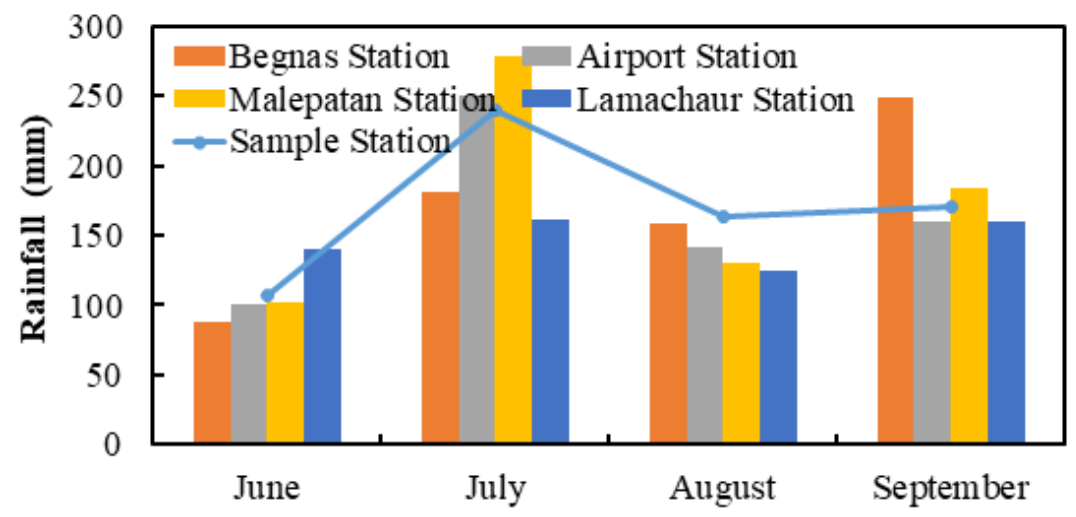

Highest, 2020

Figure 11: Graph for monthly highest of rainfall (June- September,2020)

In case of June, highest rainfall was recorded in Malepatan, however due to Kringing interpolation, data was autocorrected and highest rainfall was shown in Lamachaur station Fig. 12 (a). The sample station recorded the heaviest amount of monthly total rainfall in July as represented by darkest blue dot in Fig. 12 (b) and in the eastern part of the Pokhara valley there was a decreasing trend of rainfall with lowest rainfall observed in Begnas. In August, 
Lamachaur and Begans station recorded greater amount of rainfall as demonstrated in Fig. 12 (c). In September, Begans received highest amount of rainfall with decreasing trend northward as

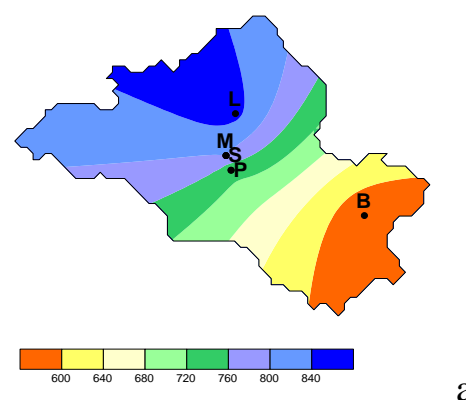

a
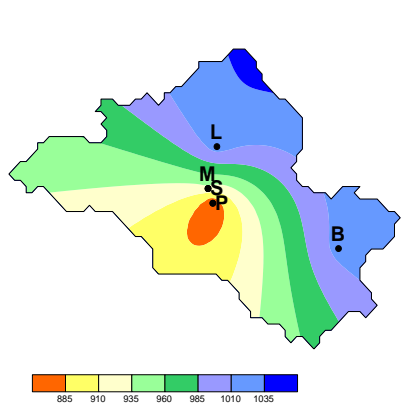

a

$\mathrm{c}$ depicted in Fig. 12 (d). Since Airport, Malepatan and sample station are located nearby the rainfall distribution during monsoon season was indistinguishable during all four seasons.

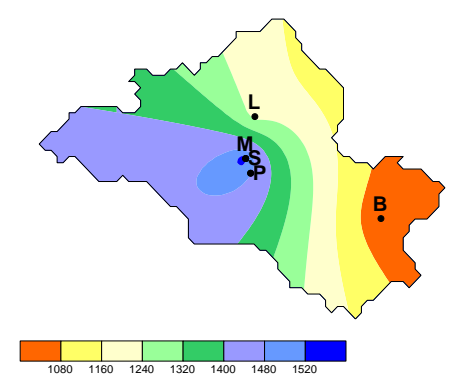

b
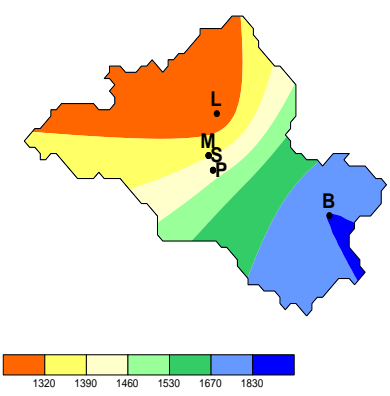

d

Figure 12: Spatial distribution of monthly rainfall; a) June, b) July, c) August, d) September

\subsection{HYSPLIT Plot:}

The HYSPLIT figure of extreme rainfall events of June and July, 2020 was plotted using the HYSPLIT model shown in Fig. 13. On $9^{\text {th }}$ June and $10^{\text {th }}$ July, 2020 highest rainfall was recorded in the respective months. Fig. 13 (a) and (b) illustrates the Westerlies dominance at three levels $500 \mathrm{~m}, 1500 \mathrm{~m}$ and $2500 \mathrm{~m}$ above ground level on both of the rainfall events. Westerlies dominance is due to Arabian Sea influence.
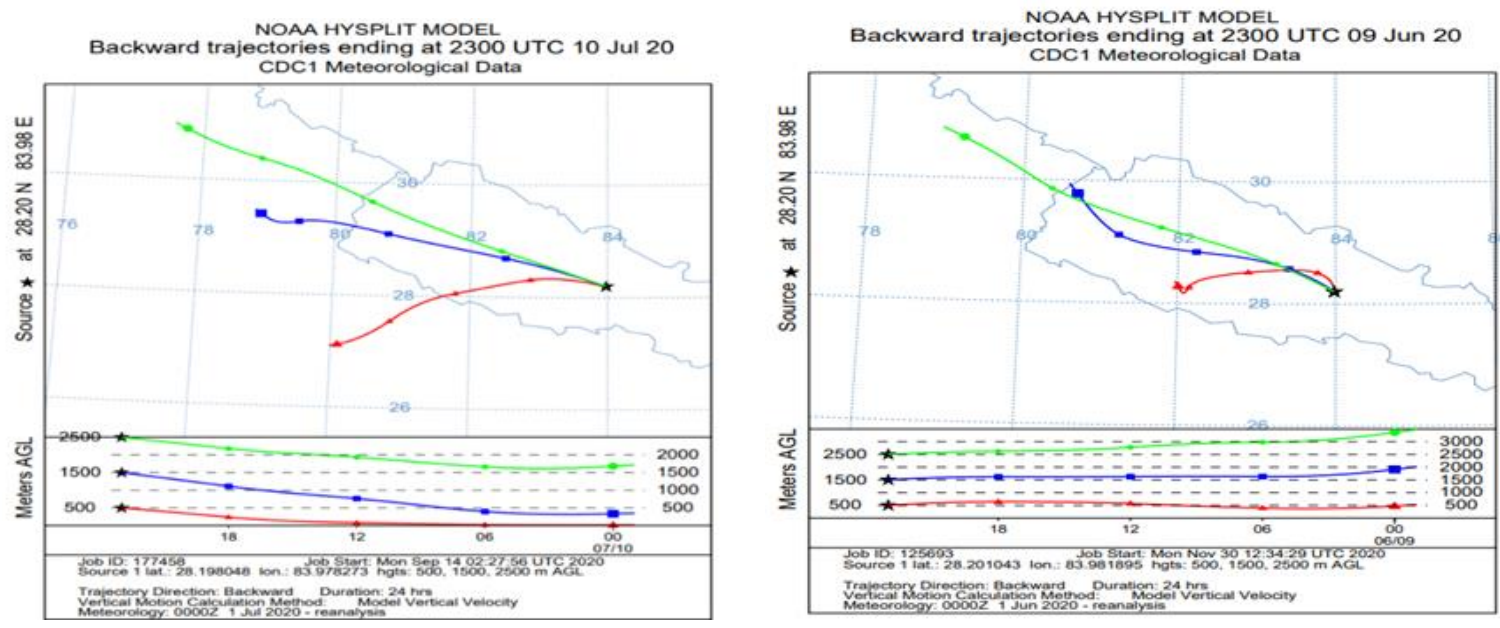

Figure 13: HYSPLIT plot of extreme rainfall events;

a) $10^{\text {th }}$ July, b) $9^{\text {th }}$ June, 2020 


\section{Conclusion:}

The rainfall estimation has always been an issue in meteorology. Due to the sparse network of meteorological instruments in Pokhara valley, the rainfall at ungauged sites is difficult to determine. The main goal of this study was to develop a formula to estimate the rainfall at the ungauged site, situated at Rastrabank Chowk Pokhara. For this purpose, daily rainfall data at the sample station was measured for four consecutive months. The analysis of the spatial distribution and variation of daily rainfall at meteorological stations as well as sample station was done to select the data for the development of the formula. It was observed that Lamachaur and Begnas stations show a higher variation of rainfall as compared to Malepatan and Airport. The rainfall data of first two months was used for calibration $\left(13^{\text {th }}\right.$ May $-13^{\text {th }}$ July,2020) and data from other two months $\left(14^{\text {th }}\right.$ July $-15^{\text {th }}$ September, 2020) was used for validation of the formula. NSE, $R^{2}$ and PBIAS statistical indices were used, to obtain the best fit between observed and predicted rainfall value. A high value of NSE and $R^{2}(0.980$ and 0.980$)$ and a lower value of PBIAS (6.437 \%) indicated lesser deviation between the observed and predicted rainfall value. Therefore, the formula for daily rainfall of a sample station, using the neighboring stations Malepatan and Airport was obtained as:

$$
S_{\mathrm{r}}=\mathrm{a} \times M_{\mathrm{r}}+\mathrm{b} \times A_{\mathrm{r}}+\mathrm{c}
$$

where, $S_{\mathrm{r}}=$ Sample Station Rainfall; $M_{\mathrm{r}}=$ Malepatan Station Rainfall; $A_{\mathrm{r}}=$ Airport Station Rainfall

$a=0.22 ; b=0.77 ; c=1.5$

Therefore, $S_{\mathrm{r}}=0.22 \times M_{\mathrm{r}}+0.77 \times A_{\mathrm{r}}+1.5$

Spatial rainfall pattern analysis using SURFER model demonstrated that there was a homogenous distribution of rainfall in Malepatan, Airport and sample stations. The temporal trend showed that the month July of 2020 had a higher amount of precipitation at Pokhara valley. From the HYSPLIT model, it was observed that the rainfall events in Pokhara valley was due to westerlies dominance. The rainfall measured locally could be used for the development of rainfall estimation techniques. The predicted rainfall could be helpful for climatological analysis and it could facilitate the design and implementation of meteorological and hydrological studies.

Spatially distributed and timely accessible precipitation data is critical for understanding spatial deviations from long-term average precipitation within the Valley. The rainfall measured locally could be used for the development of rainfall estimation techniques. This study could be the reference for further study in the same type of research field. The continuation of the study can be performed with a longer period for calibration and validation. The predicted rainfall could be helpful for climatological analysis and it could facilitate the design and implementation of meteorological and hydrological studies.

\section{References:}

[1] D. Aryal, Y. N. Rosoff, and L. P. Devkota, "A Severe Hailstorm at Pokhara: CAPE Stability Index Calculations," J. Geosci. Geomatics, vol. 3, no. 5, pp. 142-153, 2015, doi: 10.12691/jgg-3-5-5.

[2] S. P.C. and M. Maki, "Challenges in Estimating Quantitative Precipitation Estimation (QPE) Using Weather Radar Observation Over the Mountainous Country of Nepal," Hydro Nepal J. Water, Energy Environ., vol. 21, no. 21, pp. 50-59, 2017, doi: 10.3126/hn.v21i0.17822.

[3] S. K. Baidya, M. L. Shrestha, and M. M. Sheikh, "Trends in daily climatic extremes of Temperature and Precipitation in Nepal," J. Hydrol. Meteorol., vol. 5, no. 1, pp. 38-51, 2008, [Online]. Available: http://soham.org.np/wpcontent/uploads/2008/03/v5-38-51.pdf.

[4] Guide to Climatological Practices, no. 100. 2018.

[5] "Rain gauge locations." [Online]. Available: https://en.wikipedia.org/wiki/Rain_gaug e. 
[6] N. Pokharel, K. Basnet, B. Sherchan, and D. Thapaliya, "Assessment of Hydropower Potential using SWAT modeling and Spatial Technology in the Seti Gandaki River, Kaski, Nepal," vol. 8 , no. $7, \quad 2020, \quad$ doi: 10.11230/ieeesem.2020.07.16017.

[7] "Nash-Sutcliffe model efficiency coefficient." 2014, [Online]. Available: https://en.wikipedia.org/ /w/index.php?title=NashSutcliffe_model _efficiency_coefficient\&oldid $=6126179$ 47.

[8] P. Aye, S. Koontanakulvong, and T. Long, "Estimation of Groundwater Flow Budget in the Upper Central Plain, Thailand from Regional Groundwater Model," Ssms.Jp, vol. 11, no. 1, pp. 90100, 2017, [Online]. Available: https://ssms.jp/wpcontent/uploads/PDF/vol11issue1/sms17_3216.pdf. 